\section{Endoscopic closure of gastrocutaneous leakage with polyglycolic acid sheets}

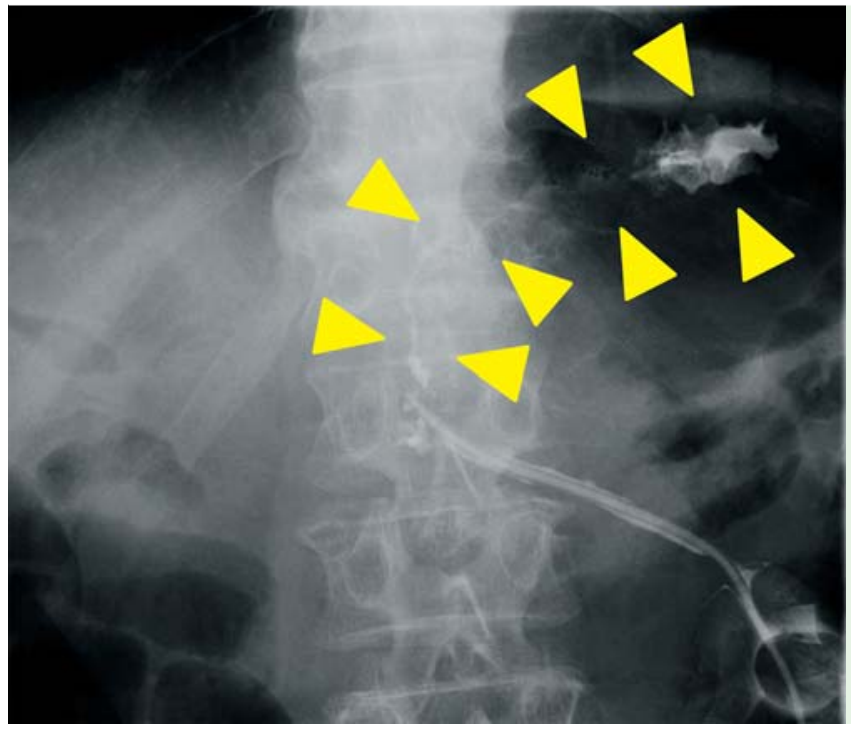

Fig. 1 Gastric and subcutaneous pooling of contrast agents and gastrocutaneous leakage (yellow arrowheads) from the drainage tube observed radiographically in a 68-year-old man following surgery for pancreatic cancer.

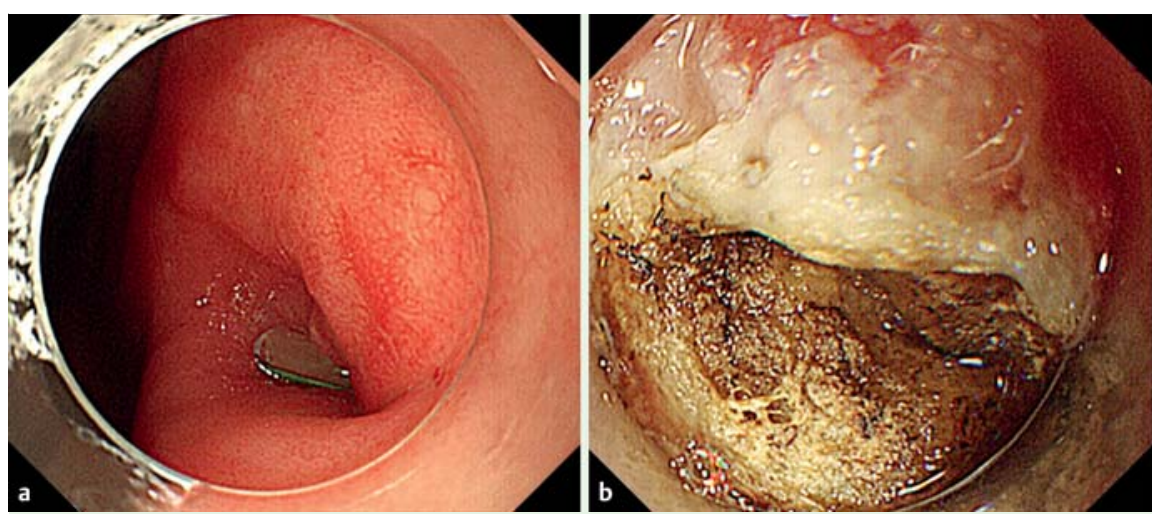

Gastrointestinal leakage after surgery is not amenable to several forms of conservative management, and reoperation strategies increase the risk for morbidity and mortality [1]. We report a case of successful endoscopic closure of a gastrocutaneous fistula with polyglycolic acid (PGA) sheets (Neoveil; Gunze Medical Division, Kyoto, Japan) and fibrin glue (Beriplast $\mathrm{P}$ Combi-Set; CSL Behring Pharma, Tokyo, Japan).

A 68-year-old man who had pancreatic cancer (T4N1M0, stage IVa) underwent neoadjuvant chemoradiotherapy followed by pancreaticoduodenectomy with major arterial resection in the department of surgical oncology of our hospital. Following surgery, gastric juice was observed around a drainage tube just above the gastrojejunal anastomosis. Gastric and subcutaneous pooling of contrast agents and a gastrocutaneous leak were diagnosed radiographically ( $\bullet$ Fig. $\mathbf{1}$ ).

Conservative treatment, including the application of cyanoacrylate glue through

Fig.2 a Endoscopic view showing the fistula and tip of the drainage tube at the lesser curvature of the antrum near the anastomosis. $\mathbf{b}$ Ablation of the mucosa around the fistula with argon plasma coagulation. c The polyglycolic acid sheet is cut into $15 \times 8-\mathrm{mm}$ pieces, and a biopsy forceps through the scope channel is used to fill the fistula with 10 of these pieces.
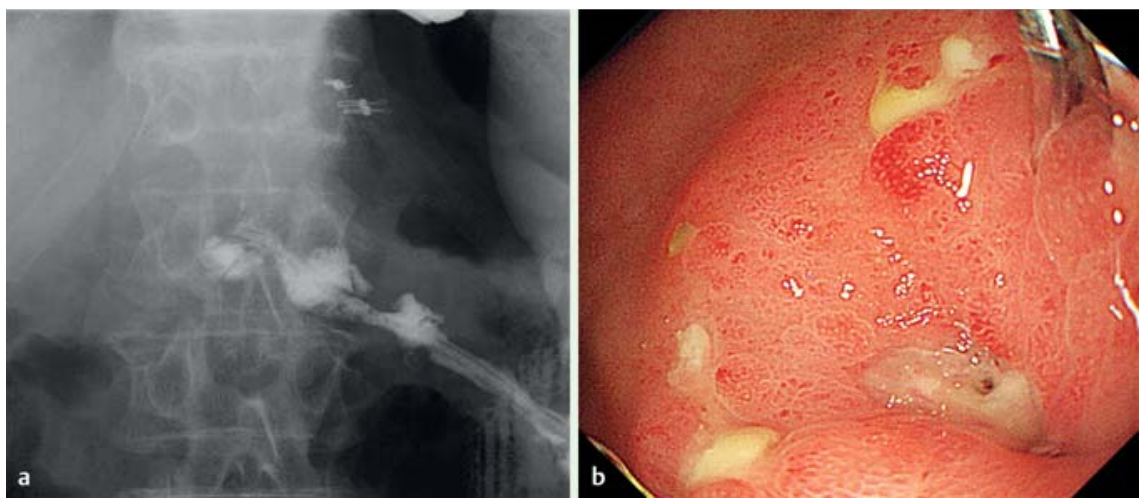

Fig. 3 a Disappearance of the leakage of contrast agents into the stomach 14 days after the procedure. $\mathbf{b}$ Endoscopic view showing fistula improvement 14 days after the first procedure.

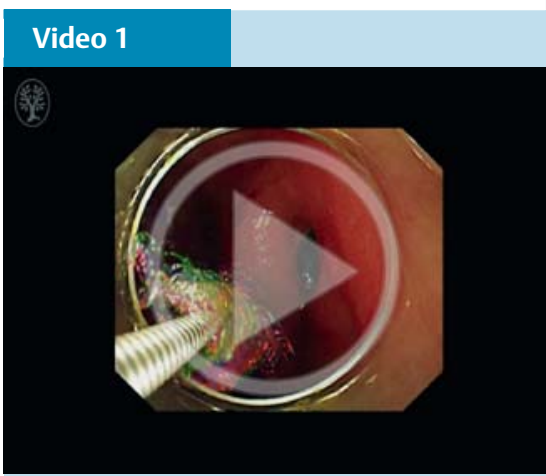

Endoscopic closure of a gastrocutaneous leak with polyglycolic acid sheets. 
the skin into the fistula, was ineffective, and leakage with pus continued for 3 months. Therefore, we attempted endoscopic closure with PGA sheets and fibrin glue. First, argon plasma coagulation was used to ablate the mucosa around the fistula, which was located at the lesser curvature of the antrum near the anastomosis ( Fig.2a, $\bullet$ Fig. 2 b; Video 1 ). Subsequently, the PGA sheet was cut into small $(15 \times 8-\mathrm{mm})$ pieces, and a biopsy forceps through the scope channel was used to fill the fistula with 10 of these pieces ( $\nabla$ Fig. 2c). Fibrin glue was applied to the PGA sheets, and endoclips were used to gather mucosa around the fistula.

This procedure was repeated 1 week later because the fistula had persisted. At 14 days after the first procedure, the gastrocutaneous leakage had disappeared ( $\bullet$ Fig.3a), and the fistula had improved ( $\bullet$ Fig. 3 b). The patient was discharged 1 month after the first procedure.

PGA sheets with fibrin glue have previously been used to close perforations and fistulas [2-5]. This case suggests that endoscopic closure with PGA sheets and fibrin glue can be used to treat gastrointestinal leakage.
Endoscopy_UCTN_Code_TTT_1AO_2AI

Competing interests: None

\section{Yasuaki Nagami ${ }^{1}$, Masatsugu Shiba ${ }^{1}$, Kazunari Tominaga', Sadaaki Yama- $z^{2}{ }^{2}$, Ryosuke Amano ${ }^{2}$, Yasuhiro Fujiwara', Tetsuo Arakawa'}

${ }^{1}$ Department of Gastroenterology, Osaka City University Graduate School of Medicine, Osaka, Japan

${ }^{2}$ Department of Surgical Oncology, Osaka City University Graduate School of Medicine, Osaka, Japan

\section{References}

1 Willingham FF, Buscaglia JM. Endoscopic management of gastrointestinal leaks and fistulae. Clin Gastroenterol Hepatol 2015 Feb 16. [Epub ahead of print]. DOI: 10.1016/ j.cgh.2015/02.010

2 Ono H, Takizawa K, Kakushima N et al. Application of polyglycolic acid sheets for delayed perforation after endoscopic submucosal dissection of early gastric cancer. Endoscopy 2015; 47 (Suppl. 01): E18-E19

3 Takimoto K, Toyonaga T, Matsuyama K. Endoscopic tissue shielding to prevent delayed perforation associated with endoscopic sub- mucosal dissection for duodenal neoplasms. Endoscopy 2012; 44 (Suppl. 02): E414E415

4 Tsuji Y, Ohata K, Gunji T et al. Endoscopic tissue shielding method with polyglycolic acid sheets and fibrin glue to cover wounds after colorectal endoscopic submucosal dissection (with video). Gastrointest Endosc 2014; 79: 151 - 155

5 Tsujii Y, Kato M, Shinzaki S et al. Polyglycolic acid sheets for repair of refractory esophageal fistula. Endoscopy 2015; 47 (Suppl. 01): E39-E40

\section{Bibliography}

Dol http://dx.doi.org/

10.1055/s-0034-1392792

Endoscopy 2015; 47: E455-E456

(c) Georg Thieme Verlag KG

Stuttgart · New York

ISSN 0013-726X

\section{Corresponding author \\ Kazunari Tominaga, MD}

Department of Gastroenterology

Osaka City University Graduate School of Medicine 1-4-3, Asahimachi

Abeno-ku

Osaka, 545-8585

Japan

Fax: +81-6-6645-3813

tomy@med.osaka-cu.ac.jp 